\title{
Synthesis of Calcium Doped TiO2 Nanomaterials and Their Visible Light Degradation Property
}

\author{
$1{ }^{\text {st }}$ Shaoyou Liu \\ College of Chemistry \& Materials Engineering \\ Kaili University \\ Kaili, China \\ Email: 1sy651204@163.com
}

\author{
$3^{\text {rd }}$ Dingze $\mathrm{Hu}$ \\ Renhuai Municipal Rural Credit Cooperative Association \\ Renhuai, China \\ Email: 704090434@qq.com.
}

\author{
$2^{\text {nd }}$ Zongyi Min \\ College of Envirnomental Science and Engineering \\ Hunan University \\ Changsha, China; \\ Email: 215900625@qq.com \\ $4^{\text {th }}$ Yunguo Liu \\ College of Environmental Science and Engineering \\ Hunan University \\ Changsha, China \\ Email: liuyunguo@hnu.edu.cn
}

\begin{abstract}
Calcium with low charge density doped $\mathrm{TiO}_{2}$ $\left(\mathrm{Ca}-\mathrm{TiO}_{2}\right)$ mesoporous nanomaterials with high specific surface areas were successfully synthesized via a simple and effective solid-state reaction route. The properties of these nanomaterials were characterized by $X$-ray diffraction (XRD), small angle X-ray scattering (SAXS), scaning electron microscopy (SEM), energy dispersive spectroscopy (EDS), $\mathbf{N}_{2}$ absorption-desorption, ultraviolet visible light spectroscopy (UV-Vis) and infrared spectrum (IR). The results show that the samples possess the high specific surface area of $101.4 \mathrm{~m}^{2} / \mathrm{g}$, spherical nanosize of 9 16 $\mathrm{nm}$, the structure of anatase $\mathrm{TiO}_{2}$, and the doped $\mathrm{Ca}^{2+}$ ion has been incorporated into the lattice or positioned on an interstitial lattice site of $\mathrm{TiO}_{2}$ with the changes of the amounts of calcium. Interestingly, the IR displays that the stretching vibrational peaks at $\sim 1630 \mathrm{~cm}^{-1}$ are assignable to the red shift of the $-\mathrm{OH}$ bond coming from the increasing of the doped calcium amount and the adsorption capacity of thiophene. Moreover, compared with the pure titanium dioxide, the $\mathrm{Ca}_{-} \mathrm{TiO}_{2}$ nanomaterials show excellent photocatalytic activities upon thiophene. For the $\mathrm{Ca}-\mathrm{TiO}_{2}$ (Ca:Ti=1:7) photocatalyst, $90.2 \%$ of the initial thiophene can be degraded by visible light irradiation at $25^{\circ} \mathrm{C}$ for $50 \mathrm{~min}$.
\end{abstract}

Keywords: Calcium doping; Titanium dioxide; Solid state reaction; Visible light degradation; Thiophene

\section{INTRODUCTION}

Thiophene is commonly regarded as a colorless, malodor, highly toxic, five membered heterocyclic compounds with a sulphur atom. It exists in soil and industry wastewater, which could migrate to groundwater, therefore, by bringing about a potential risk to human and animals. Although biological degradation of thiophene is found, the degradation rate is very slow [1], accompanied by the production of ill-defined detrimental compounds. Fortunately, recent studies reveal that semiconductor titania-mediated photodegradation of toxic compound is more attractive due to its low cost, strong oxidizing power and good chemical stability [2-4]. For instance, Yu et al. [5] found that $90 \%$ of pentachlorophenol could be degraded over the $\mathrm{NiO} / \mathrm{TiO}_{2}$ composite. Liu [6] reported that the Congo red could be degraded by Al-doped $\mathrm{TiO}_{2}$ nanopowder irradiated by various lights. However, the large band gap $(3.2 \mathrm{eV})$ and relatively high recombination rate of photogenerated hole-electron pairs of anatase $\mathrm{TiO}_{2}$ have limited its widespread application in environmental protection. Up to date, effective approaches to overcome these challenges are to dope $\mathrm{TiO}_{2}$ with metal and nonmetal elements for enlarging the light absorption range of $\mathrm{TiO}_{2}$. Among these methods, transition metal, rare earth and noble metal ion doping [7-9] have been widely adopted to control the position of conduction band or valence band of $\mathrm{TiO}_{2}$, which could make the electrons excitable irradiated by visible light to generate the photoelectron-hole pairs. Besides, it is scarce to detailedly investigate the alkaline-earth metal ion doping of $\mathrm{TiO}_{2}$ and their photocatalytic properties [10]. Noticeably, $\mathrm{TiO}_{2}$, as an $\mathrm{n}$ type semiconductor, when the electron density of the doped $\mathrm{TiO}_{2}$ decreases to some extents, could change into a $\mathrm{p}$ type semiconductor, which would change the photocatalytic activity [11]. To extend the absorption solar light range of $\mathrm{TiO}_{2}$ and to reduce the hole-electron recombination probability, calcium, in this work, was first employed to dop $\mathrm{TiO}_{2}$ for obtaining improved $\mathrm{Ca}-\mathrm{TiO}_{2}$ mesoporous nanomaterials by a facile solid state reaction method in the broader sense and the effects of the calcium-doped content was investigated. Furthermore, the photodegradation efficiency of pure $\mathrm{TiO}_{2}$ and $\mathrm{Ca}-\mathrm{TiO}_{2}$ nanopowder was comparatively studied by photodegradation of the thiophene solution.

\section{EXPERIMENTAL}

\section{A. Materials}

Tetrabutyl orthotitanate (TBOT, 98\% (by mass)), Ca $\left(\mathrm{NO}_{3}\right)_{2} \cdot 4 \mathrm{H}_{2} \mathrm{O}$ (A.R.), thiophene (A.R), cetyltrimethy lammoniumbromide (CTAB, A.R.) and pure $\mathrm{TiO}_{2}$ (surface area, $49.4 \mathrm{~m}^{2} / \mathrm{g}$ ) are provided by Shanghai Chemical Reagent Plant, China. All chemicals were used without 
further treatment.

\section{B. Synthesis}

The synthesis of $\mathrm{Ca}-\mathrm{TiO}_{2}$ photocatalyst is as follows: $\mathrm{Ca}\left(\mathrm{NO}_{3}\right)_{2} \cdot 4 \mathrm{H}_{2} \mathrm{O}$ and $\mathrm{CTAB}$ were firstly mixed and ground in a mortar for $15 \mathrm{~min}$, then, the obtained mixture was mixed with TBOT and ground for $10 \mathrm{~min}$. Then, the obtained mixture was mixed with TBOT and ground for $10 \mathrm{~min}$. The feed molar ratio of $\mathrm{Ca}\left(\mathrm{NO}_{3}\right)_{2} .4 \mathrm{H}_{2} \mathrm{O}$ :TBOT is $1: 4,1: 5,1: 6$, $1: 7,1: 8,1: 9,1: 10,1: 12$, respectively, and CTAB is $10 \mathrm{wt} \%$ for the total weight of TBOT and $\mathrm{Ca}\left(\mathrm{NO}_{3}\right)_{2} \cdot 4 \mathrm{H}_{2} \mathrm{O}$. The resulting viscous mixture was put into a beaker, followed by aging for $4 \mathrm{~h}$ and heated at $413 \mathrm{~K}$ in thermoelectric oven for $1.5 \mathrm{~h}$ to accelerate the reaction. After cooling to room temperature, the solid sample was ground and washed 5 8 times repeatedly with distilled water and then dried at 373 $\mathrm{K}$. The samples were calcined in a muffle furnace at $823 \mathrm{~K}$ for $6 \mathrm{~h}$ with a heated temperature rate of $1{ }^{\circ} \mathrm{C}$ to remove the residual surfactant. The obtained sample was named as Ca-TiO 2 (1:4), Ca-TiO 2 (1:5), Ca-TiO $(1: 6), \mathrm{Ca}-\mathrm{TiO}_{2}$ (1:7), $\mathrm{Ca}_{-} \mathrm{TiO}_{2}$ (1:8), Ca-TiO 2 (1:9), Ca-TiO 2 (1:10), Ca-TiO $(1: 12)$ corresponding to the feed molecular ratio of $\mathrm{Ca}\left(\mathrm{NO}_{3}\right)_{2} \cdot 4 \mathrm{H}_{2} \mathrm{O}$ : TBOT, respectively.

\section{Characterization}

X-ray diffraction (XRD) studies of the sample were performed on a PANalytical diffractometer $(\mathrm{CuK} \alpha$ radiation, wavelength $0.15406 \mathrm{~nm})$. The diffraction data were recorded for $2 \theta$ angles between $5^{\circ}$ and $70^{\circ}$ with a scanning speed of $0.02\left(^{\circ}\right) \cdot \mathrm{s}^{-1}$. Scanning electron micrography (SEM) and energy dispersive spectroscopy (EDS) were performed on a JSM-6700F electron microscopy, with an accelerating voltage of $20 \mathrm{kV}$ and a resolution of $1 \mathrm{~nm}$. Nitrogen adsorption-desorption isotherm was obtained at $77 \mathrm{~K}$ with a Gemini-2390 VII type gas sorption and porosimetry instrument. Before the adsorption measurement, the sample was heated from room temperature to $413 \mathrm{~K}$ and evacuated to $10^{-3} \mathrm{~Pa}$, and then kept at that temperature and vacuum outgas for $4 \mathrm{~h}$. The specific surface area was determined by the BET method, assuming full surface coverage with nitrogen. UV-Vis diffuse reflection spectra were measured using a UV-2550 spectrometer. The spectra were collected at $200-700 \mathrm{~nm}$ referenced to $\mathrm{BaSO}_{4}$. The information of material surface structure property was carried out on the Perkin Elmer spectrum 65 infrared spectrometer with a range of 4000-400 $\mathrm{cm}^{-1}$ and a spectral resolution of $1 \mathrm{~cm}^{-1}$. The content of $\mathrm{Ca}$ was determined by the TAS-986 atomic absorption spectrophotometer with with analytical line $\lambda_{\mathrm{Ca}}$ $=422.7 \mathrm{~nm}$. The background was deducted by deuterium lamp; an air flow capacity of $6 \mathrm{~L} / \mathrm{min}$, a lamp electric current of $35 \mathrm{~mA}$, a spectrum bandwidth of $0.1 \mathrm{~nm}$, height of burner of $6 \mathrm{~mm}$, and acetylene flow capacity of $2 \mathrm{~L} / \mathrm{min}$ were used.

\section{Photodegradation}

The photocatalytic decomposition of thiophene over the photocatalysts was carried out in a XPA-VII photochemical reactor (Nanjing Xujiang Electromechanical Factory, China). A $300 \mathrm{~W}$ metal halogen lamp assisted with Toshiba
B-47 optical filter $(\lambda>410 \mathrm{~nm})$ was used as a visible light source. In each run, the photocatalyst of $0.02 \mathrm{~g}$ was added into $20 \mathrm{~mL}$ of thiophene solution $\left(c_{\mathrm{o}}=50 \mathrm{mg} / \mathrm{L}\right)$ with $\mathrm{pH}$ of 7.45. Prior to the photodegradation experiment, the catalyst was allowed to reach a steady state with thiophene in dark for $60 \mathrm{~min}$. Then, the adsorption capacity of the samples was determined. Later, the photodegradation reaction was initiated under visible light irradiation. The reaction system was kept continuously under magnetic stirring at a rate of $600 \mathrm{rpm}$, and the reaction temperature was controlled at 298 $\pm 1 \mathrm{~K}$ by a water-cooling system. The concentration of the residual thiophene $\left(c_{\mathrm{t}}\right)$ was measured at a fixed time interval by TU-1900 spectrometer at its maximum absorption wavelength of $229 \mathrm{~nm}$.

\section{RESULTS AND DISCUSSION}

\section{A. XRD and SEM Analysis}

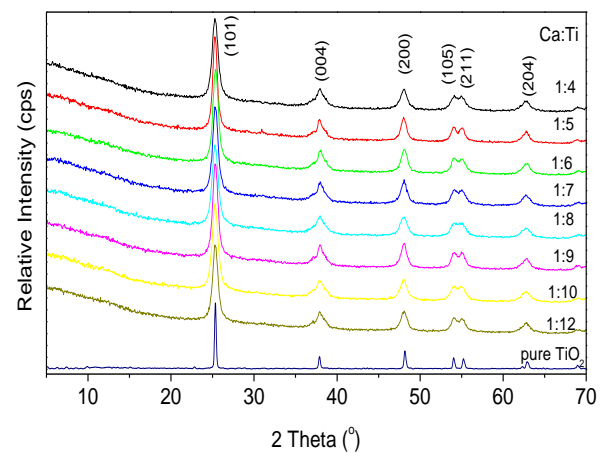

Figure 1. XRD patterns for the $\mathrm{Ca}-\mathrm{TiO}_{2}$ samples

The wide-angle XRD patterns of the samples are presented in Fig.1. The XRD patterns of all Ca- doped samples and pure $\mathrm{TiO}_{2}$ can be assigned to anatase $\mathrm{TiO}_{2}$ with reflection peaks in(101), (004), (200), (105), (211) and (204) crystal planes. The average crystallite sizes and crystal lattice strain of all the samples are given in Table 1, which are determined by the XRD software. From the data in table 1 , it can be seen that all the crystallite sizes of $\mathrm{Ca}-\mathrm{TiO}_{2}$ samples are smaller than the pure $\mathrm{TiO}_{2}$, indicating the doping of calcium effectively inhibits the growth of $\mathrm{TiO}_{2}$ crystallites. Moreover, the average crystallite sizes $(L)$ increase $\left(L_{\mathrm{Ca}-\mathrm{TiO}(1: 4)}<L_{\mathrm{Ca}-\mathrm{TiO} 2}\right.$ (1:5) $)$ and then gradually decrease in the following sequence of $L_{\mathrm{Ca}-\mathrm{TiO} 2(1: 5)}>L_{\mathrm{Ca}-\mathrm{TiO} 2}$ ${ }_{(1: 6)}>L_{\mathrm{Ca}-\mathrm{TiO} 2(1: 7)}>L_{\mathrm{Ca}-\mathrm{TiO} 2(1: 8)}>L_{\mathrm{Ca}-\mathrm{TiO} 2(1: 9)}>L_{\mathrm{Ca}-\mathrm{TiO} 2(1: 10)}>$ $L_{\mathrm{Ca}-\mathrm{TiO} 2(1: 12)}$. Since the ion radius of $\mathrm{Ca}^{2+}(0.099 \mathrm{~nm})$ is larger than that of $\mathrm{Ti}^{4+}(0.068 \mathrm{~nm})$, the $\mathrm{Ca}^{2+}$ ion doped enters into the lattice of $\mathrm{TiO}_{2}$ with more difficultly than the other metal ion with similar ion radius of $\mathrm{Ti}^{4+}$. In addition, when a $\mathrm{Ca}^{2+}$ ion is located in a substitutional site of $\mathrm{TiO}_{2}$, the electron density of the doped $\mathrm{TiO}_{2}$ slightly decreases, and when decreasing of the feed molar ratio of $\mathrm{Ca}: \mathrm{Ti}$, the electron density of $\mathrm{Ca}$ doped $\mathrm{TiO}_{2}$ sample relatively increases. Moreover, no other X-ray diffraction peaks are found in figure 1 . The analytic results of the doped elemental component are listed in Table 1. For the alkaline-earth calcium metal, all above results confirm that 
the key approach is isomorphous substitution of the primary condition, and the limittance of ionic radius is relegated to secondary status in the heterovalent isomorphism circumstances. Typically, the scanning electronmicrograph image (the inset of fig. 2 is EDS analysis of $\mathrm{Ca}-\mathrm{TiO}_{2}(1: 4)$ ) shown in fig. 2 confirms that the sample $\mathrm{Ca}^{-\mathrm{TiO}_{2}}(1: 4)$ exhibits the shape of spherical particle and the particle sizes range change from 9 to $16 \mathrm{~nm}$, which is consistent with the XRD analysis $(10.7 \mathrm{~nm})$.

TABLE I. THE CHARACTERISTIC PARAMETERS AND CONTENT OF THE SAMPLE

\begin{tabular}{|c|c|c|c|c|c|}
\hline Sample & $\begin{array}{l}\text { Crystallite } \\
\text { size /nm }\end{array}$ & $\begin{array}{c}\text { Lattice } \\
\text { stress } / \times 10^{-4}\end{array}$ & $\begin{array}{l}\mathrm{BET} \\
/ \mathrm{m}^{2} / \mathrm{g}\end{array}$ & $\begin{array}{c}\text { Bandgap } \\
\text { /eV }\end{array}$ & $\begin{array}{c}\mathrm{Ca} \\
\text { /at \% }\end{array}$ \\
\hline $\mathrm{Ca}^{-\mathrm{TiO}_{2}}(1: 4)$ & 10.7 & 1.651 & 101.4 & 2.986 & 3.67 \\
\hline $\mathrm{Ca}-\mathrm{TiO}_{2}(1: 5)$ & 14.9 & 1.225 & 89.6 & 3.048 & 3.12 \\
\hline $\mathrm{Ca}-\mathrm{TiO}_{2}(1: 6)$ & 13.7 & 1.331 & 92.3 & 3.077 & 2. 62 \\
\hline $\mathrm{Ca}-\mathrm{TiO}_{2}(1: 7)$ & 12.5 & 1.431 & 89.3 & 3.200 & 2.05 \\
\hline $\mathrm{Ca}-\mathrm{TiO}_{2}(1: 8)$ & 12.1 & 1.467 & 93.5 & 3.127 & 1.75 \\
\hline $\mathrm{Ca}-\mathrm{TiO}_{2}(1: 9)$ & 11.8 & 1.503 & 78.1 & 3.144 & 1.23 \\
\hline $\mathrm{Ca}-\mathrm{TiO}_{2}(1: 10)$ & 10.7 & 1.651 & 73.2 & 3.190 & 0.92 \\
\hline $\mathrm{Ca}-\mathrm{TiO}_{2}(1: 12)$ & 10.3 & 1.702 & 69.8 & 3.193 & 0.81 \\
\hline Pure $\mathrm{TiO}_{2}$ & 25.4 & 0.068 & 49.4 & 3.149 & 0 \\
\hline
\end{tabular}

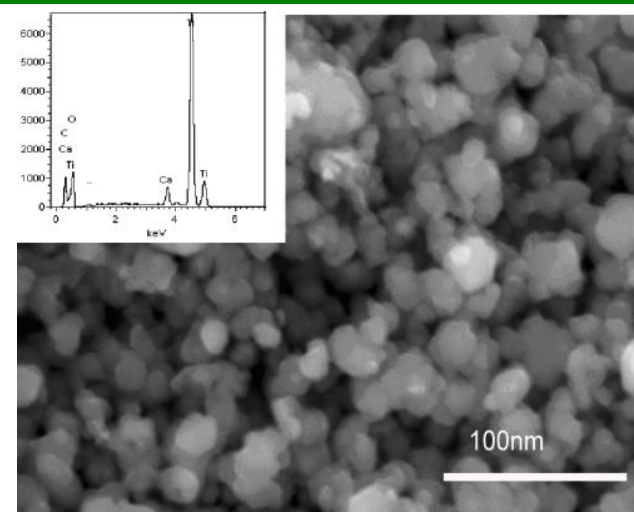

Figure 2. SEM image of the sample $\mathrm{Ca}-\mathrm{TiO}_{2}(1: 4)$.

\section{B. $\quad U V$-Vis Absorption Spectra}

Figure 3 illustrates the UV-vis absorption spectra of eight $\mathrm{Ca}-\mathrm{TiO}_{2}$ and pure $\mathrm{TiO}_{2}$ samples. The small chart in the upper right conner of Fig.3 is an enlarged figure from 360 to $420 \mathrm{~nm}$. Clearly for the absorption edge position of Ca-doped $\mathrm{TiO}_{2}$ samples, a part of the samples move toward shorter wavelength, comparing with pure $\mathrm{TiO}_{2}$ powders, another part of the samples exhibit red shift, meaning the band gap of Ca-doped $\mathrm{TiO}_{2}$ samples decreases or increases after calcium doping. The band gap widening should be attributed to the decrease of $\mathrm{TiO}_{2}$ crystal size [12]. From the table 1, when the molar ratio of $\mathrm{Ca}$ :Ti exceed 1:5, the size of $\mathrm{TiO}_{2}$ crystal decreases from 14.9 to $10 \mathrm{~nm}$, indicating that the band structure of $\mathrm{TiO}_{2}$ in $\mathrm{Ca}-\mathrm{TiO}_{2}$ becomes quantized. Larger band gap energy of $\mathrm{Ca}-\mathrm{TiO}_{2}$ can result in larger thermodynamic driving force and accelerate charge carrier transfer rates in the normal Marcus region than its bulk phase counterparts. Moreover, the calcium doping can lead to the formation of partial $\mathrm{Ti}^{3+}$, which limits the recombination rate of charge carriers. In addition, it can be observed from fig. 3 that the absorbance of $\mathrm{TiO}_{2}$ at 200-350nm increases with the decrease of doped calcium amount, and the visible light absorption range of Ca-doped $\mathrm{TiO}_{2}$ samples also decreases correspondingly, which can result in the improvement of the photocatalytic activity in the UV region. The bandgap $\left(E_{\mathrm{g}}\right)$ can be calculated using the equation: $E_{\mathrm{g}}(\mathrm{eV})=1240 \lambda_{\mathrm{g}}$, where $\lambda_{\mathrm{g}}$ is an intersection value for the vertical part and horizontal part of the spectrum. Fig. 4 shows the bandgaps of the samples. Obviously, the bandgap of Ca-doped $\mathrm{TiO}_{2}$ samples increases with the decreases of molar ratio of Ca:Ti except for $\mathrm{Ca}: \mathrm{Ti}=1: 7$, suggesting that the $\mathrm{Ca}^{-\mathrm{TiO}_{2}}$ (1:7) photocatalyst has different performance for the photocatalytic activity.

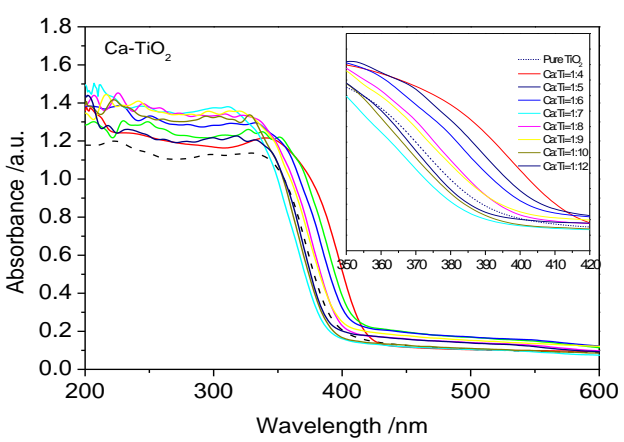

Figure 3. UV-vis absorption spectra of $\mathrm{Ca}-\mathrm{TiO}_{2}$ samples.

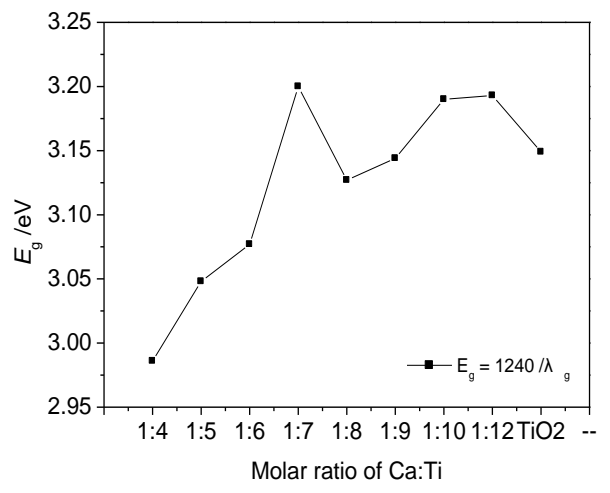

Figure 4. Bandgap of the $\mathrm{Ca}-\mathrm{TiO}_{2}$ samples.

\section{IR Spectra}

Figure 5 shows the IR spectra of pure $\mathrm{TiO}_{2}$ and Ca-doped $\mathrm{TiO}_{2}$ samples. The broad peaks at $\sim 3600, \sim 3100$ and $\sim 1630 \mathrm{~cm}^{-1}$ correspond to the surface-adsorbed water and hydroxyl groups, respectively. As the molar ratio of $\mathrm{Ca}$ Ti increases, the change of band shape is observed in two peaks in Fig.5. A distinct peak around $1040 \mathrm{~cm}^{-1}$ can be seen, which belongs to the $\mathrm{Ca}-\mathrm{O}$ bond in the $\mathrm{CaO}$ crystal. However, this peak cannot be found on the undoped and low-content Ca-doped $\mathrm{TiO}_{2}$ samples, which is agreement with the result of XRD. Another peak around $1390 \mathrm{~cm}^{-1}$ is present in the IR spectra of Ca- $\mathrm{TiO}_{2}$ samples but absent for the pure $\mathrm{TiO}_{2}$, and its intensity increases with the increase of calcium content. Therefore, the peak around $1140 \mathrm{~cm}^{-1}$ may be attributed to Ti-O-Ca bonds in this work. Interestingly, the intensity of vibration of hydroxyl displays difference each other, which indicates the existence of 
various polarity on the $\mathrm{Ca}$-doped $\mathrm{TiO}_{2}$ samples surface, and surface polarity increases with the decrease of the molar ratio of $\mathrm{Ca}$ :Ti. When the molar ratio of $\mathrm{Ca}$ : Ti is lower than 1:7, the polarity on the $\mathrm{Ca}$-doped $\mathrm{TiO}_{2}$ samples surface decreases. Assuredly, the various $\mathrm{Ca}$ amount introduction of $\mathrm{Ca}-\mathrm{TiO}_{2}$ makes the photocatlysts possess more surface hydroxyl groups, which favors not only the trapping of electrons to enhance the separation efficiency of electron-hole pair but also the formation of surface free radical $(\mathrm{OH})$ to enhance the photocatalytic degradation of organic waste water [13-14].

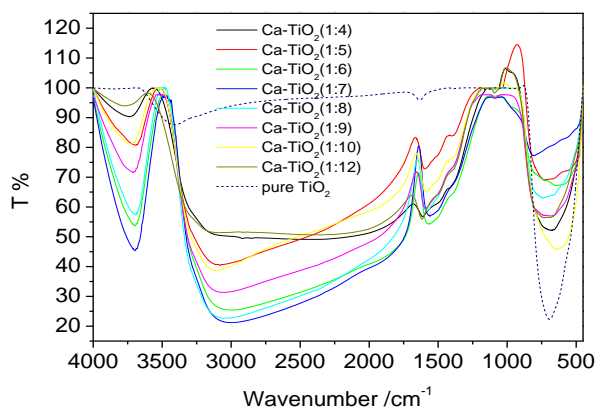

Figure 5. IR spectra of Ca-doped $\mathrm{TiO}_{2}$ samples

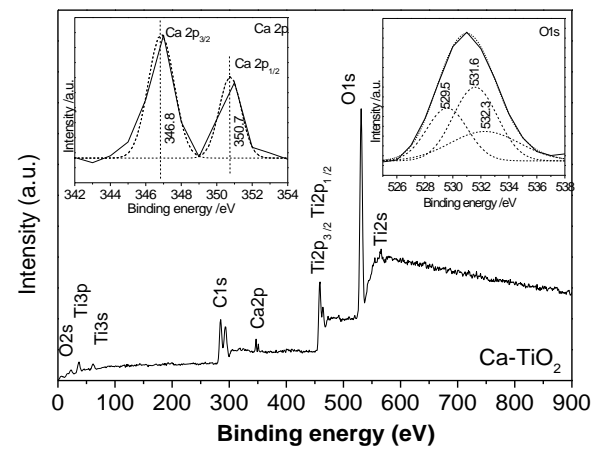

Figure 6. The XPS survey spectrum of $\mathrm{Ca}-\mathrm{TiO}_{2}$ with molar ratio of Ca:Ti(1:4) sample.

\section{XPS Studies}

In order to determine the chemical states of calcium element in $\mathrm{TiO}_{2}$, the XPS spectra of the $\mathrm{Ca}-\mathrm{TiO}_{2}(1: 4)$ sample was discussed (see Fig.6). From the XPS survey spectrum of $\mathrm{Ca}^{-\mathrm{TiO}_{2}}$ (1:4) sample, it can be observed that the sample includes $\mathrm{Ti}, \mathrm{O}, \mathrm{C}$, and $\mathrm{Ca}$ elements, and the binding energies of $\mathrm{Ti} 2 \mathrm{p}, \mathrm{O} 1 \mathrm{~s}, \mathrm{Ca} 2 \mathrm{p}$, and $\mathrm{C} 1 \mathrm{~s}$ are 458.7, 530,347 and $284 \mathrm{eV}$, respectively. The $\mathrm{C}$ element can be ascribed to the residual carbon from precursor solution and the adventition hydrocarbon from XPS instrument itself. The small chart in the upper left conner of fig. 6 is the high-resolution XPS specrum of $\mathrm{Ca} 2 \mathrm{p}$ region on the surface of $\mathrm{Ca}-\mathrm{TiO}_{2}(1: 4)$ sample. The $\mathrm{Ca} 2 \mathrm{p}$ region contains two peaks at 346.8 and $350.7 \mathrm{eV}$, corresponding to the binding energy of $\mathrm{Ca} 2 \mathrm{p}_{3 / 2}$ and $\mathrm{Ca} 2 \mathrm{p}_{1 / 2}$, respectively. The broad $\mathrm{O} 1 \mathrm{~s}$ region of $\mathrm{Ca}-\mathrm{TiO}_{2}(1: 4)$ can be fitted by three peaks at 529.5, 531.6 and $532.3 \mathrm{eV}$, which are Ti-O-Ti bond in $\mathrm{TiO}_{2}, \mathrm{Ca}-\mathrm{O}-\mathrm{Ti}$ bond, and hydroxyl groups, respectively, further confirming the presence of $\mathrm{Ca}-\mathrm{O}$ bond. The results show $\mathrm{Ca}$ element exists in the state of $\mathrm{Ca}^{2+}$ after calcination.

\section{E. Adsorption and Photodegradation of Thiophene}

Previous studies show that the anatase $\mathrm{TiO}_{2}$ is found to be more active toward the photocatalytic degradation of organic substance than the rutile $\mathrm{TiO}_{2}$ [15], so, we chose the anatase $\mathrm{TiO}_{2}$ as the basis of our work. Considering the electronic absorption and surface area data (see table 1), thiophene concentration was monitored in the bulk solution for 60 minutes until adsorption/ desorption equilibrium was reached, thus generating isotherms adsorption for the same concentration $(50 \mathrm{mg} / \mathrm{L})$ of thiophene (see Fig.7). As shown in Fig.7, the maximum and minimal adsorption capacity of the $\mathrm{Ca}-\mathrm{TiO}_{2}$ (1:7) and pure $\mathrm{TiO}_{2}$ samples were obtained, respectively. Another $\mathrm{Ca}$-doped $\mathrm{TiO}_{2}$ samples prepared in the same manner reveal that the thiophene adsorption capacity first increases and then decreases. When the molar ratio of $\mathrm{Ca}: \mathrm{Ti}$ is greater than $1: 7$, thiophene adsorption capacity on the $\mathrm{Ca}$-doped $\mathrm{TiO}_{2}$ surfaces increases, once the molar ratio of $\mathrm{Ca}$ : $\mathrm{Ti}$ is less than $1: 7$, thiophene adsorption capacity reduces. Based on the adsorption studies, the data from the visible light degradation of thiophene were obtained in Fig.7. For comparison, photocatalytic degradation of thiophene on commercial pure $\mathrm{TiO}_{2}$ was also performed under the same conditions. Fig.7 shows that after irradiating under visible light for $50 \mathrm{~min}, 90.2 \%$ and $19.1 \%$ of thiophene degraded by the $\mathrm{Ca}-\mathrm{TiO}_{2}$ (1:7) photocatalyst and the pure $\mathrm{TiO}_{2}$ are present, respectively. Moreover, the visible light degradation rate of thiophene is positive to adsorption capacity over the photocatalysts. Surprisingly and interestingly, the specific surface area of Ca-doped $\mathrm{TiO}_{2}$ catalysts is less than two times of the pure $\mathrm{TiO}_{2}$ (table 1), but the photocatalytic degradation rate of thiophene over Ca-doped $\mathrm{TiO}_{2}$ photocatalysts is higher than twice of the pure $\mathrm{TiO}_{2}$, indicating the surface area doesn't exist in linear relationship with the degradation rates, Therefore, thiophene adsorption is not simply ascribed to the high surface area. Ulteriorly the appropriate chemical compositions of $\mathrm{Ca}$-doped $\mathrm{TiO}_{2}$ mesoporous materials have played a significant role and thiophene is also sensitive to the calcium sites on these materials surface. Some researches indicate that the pollutant adsorption on the catalyst surface plays a very important role, and increasing the adsorption capacity of pollutant can improve the efficiency of photons during the photocatalytic process, leading to faster degradation of pollutant [16]. Thus, we conclude that degradation capacity of thiophene is directly relative to the distribution, quantity and vibration intensity of hydroxyl groups on the Ca-doped $\mathrm{TiO}_{2}$ catalysts surface. Sulphur heteroatom with partial positive charge in thiophene combines easily with the hydroxyl groups, and its combination strength is proportional to quantity and distribution of hydroxyl groups. Evidently, these are in agreement with the results of infrared spectra. In addition, the $\mathrm{Ca}$ content in $\mathrm{Ca}$-doped $\mathrm{TiO}_{2}$ catalysts isn't proportional to its photocatalytic activity, suggesting that a prerequisite for an effective dopant involves the possibility of charge trapping and migration to the surface of catalysts. The calcium ions doped are located mainly on the shallow 
surface of $\mathrm{TiO}_{2}$ and can induce some defects. These defects could become the centers of shallow electrons or holes traps to improve efficiently the separation of the electrons and holes, resulting in higher photocatalytic activity of Ca-doped $\mathrm{TiO}_{2}$ catalysts.

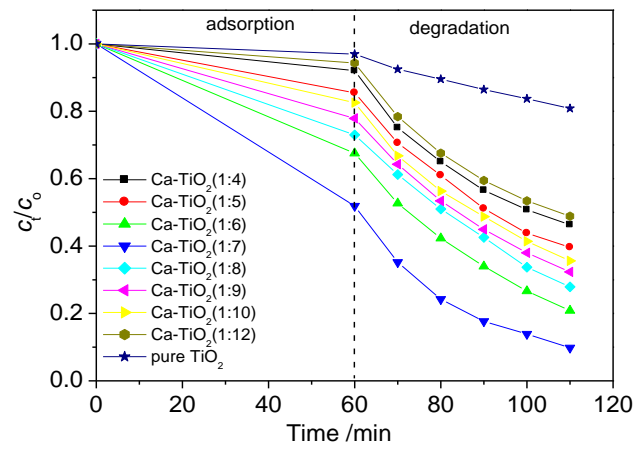

Figure 7. The adsorption and degradation of thiophene on the various $\mathrm{Ca}-\mathrm{TiO}_{2}$ samples.

\section{CONCLUSIONS}

$\mathrm{Ca}-\mathrm{TiO}_{2}$ nanoparticles were successfully prepared by a simple solid-state reaction method. The results show that the $\mathrm{Ca}-\mathrm{TiO}_{2}$ sample presents an excellent visible light absorption and degradation property. The doped $\mathrm{Ca}$ contents in $\mathrm{TiO}_{2}$ would be increased with augmenting of molar ratio of $\mathrm{Ca}$ :Ti. In addition, the doped $\mathrm{Ca}$ plays an essential role not only changing the visible absorption of $\mathrm{TiO}_{2}$ but also decreasing particle size to increase the specific surface area. $\mathrm{Ca}-\mathrm{TiO}_{2}$ possess the outstanding degradation thiophene ability under visible light irradiation, being much superior to pure $\mathrm{TiO}_{2}$, which was probably due to the enhanced thiophene absorption ability and effective depression of photogenerated hole-electron recombination.

\section{ACKNOWLEDGEMENTS}

This project was supported by the Education Quality Promotion Foundation of Department of education, Guizhou Province, China (No. [2011] 278-01); Research of Natural Science and Technology Foundation of Guizhou Province (No. [2010]2006, and No. [2011]2315), China; and Guizhou Province Characteristic Leading Academic Discipline Project in Material Physics and Chemistry (No.[2011]208); and Construction Fund of Guizhou Province Characteristic Key Laboratory (No.[ 2012] 225).

\section{REFERENCES}

[1] Tian Xiao-Juan, Tang Ling-Tian, Peng Li-E, et al. Screening and identification of microbial strains for the desulfurization of petroleum. Earth Science Frontiers, 2008,15(6):192-198 (in Chinese).

[2] Hoffmann M R, Martin S T, Choi W Y. Bahnemannt D. W. Environemental applications of semiconductor photocatalysis. Chem. Rev., 1995, 95(1): 69- 96

[3] Linsebigler A L, Lu G Q, Yates J T. Photocatalysis on $\mathrm{TiO}_{2}$ surfaces: principles, mechanisms, and selected results. Chem. Rev., 1995, 95(3): 735-758.

[4] Wu X Y, Yin S, Dong Q, Guo C S, Kimura T, Matsushita J, Sato T. Photocatalytic properties of $\mathrm{Nd}$ and $\mathrm{C}$ codoped $\mathrm{TiO}_{2}$ with the whole range of visible light absorption. J. Phys. Chem. C, 2013, 117(16): 8345-8352.

[5] Yu J G, Wang W G, Cheng B. Synthesis and enhanced photocatalytic activity of a hierarchical porous flower like $\mathrm{p}-\mathrm{n}$ junction $\mathrm{NiO} / \mathrm{TiO}_{2}$ photocatalyst. Chem. Asian J, 2010, 5(12): 2499- 2506.

[6] Liu S Y, Liu G C, Feng Q G. Al-doped $\mathrm{TiO}_{2}$ mesoporous materials: synthesis and photo- degradation properties. J Porous Mater, 2010, 17(2):197-206.

[7] Hanaor D A H, Sorrell C C. Review of the anatase to rutile phase transformation. J. Mater. Sci., 2011, 46(4): 855-874.

[8] Primo A, Corma A, Garcia H. Titania supported gold nanoparticles as photocatalyst. Phys. Chem. Chem. Phys., 2011, 13(3): 886-910.

[9] Kisch H, Macyk W. Visible-light photocatalysis by modified titania. ChemPhysChem, 2002, 3(5): 399-400.

[10] Chen C J, Wu J M. Sintering behavior of niobium- and calcium-doped $\mathrm{TiO}_{2}$ ceramics. Materials Science and Engineering: B, 1989, 5(1):5-15.

[11] Li Y X, Peng S Q, Jiang F Y, Lu G X, Li S B. Effect of doping $\mathrm{TiO}_{2}$ with alkaline-earth metal ions on its photocatalytic activity. J. Serb. Chem. Soc., 2007, 72 (4):393-402.

[12] Lee S, Cho I S, Noh J H, Hong K S, Han G S, Jung H S, Jeong S, Lee C, Shi H. Correlation of anatase particle size with photocatalytic properties. Phys. Status Solidi A, 2010, 207(10): 2288-2291.

[13] Tian G H, Fu H G, Jing L Q, Pan K. Synthesis and photocatalytic activity of stable nanocrystalline $\mathrm{TiO} 2$ with high crystallinity and large surface area. J. Hazard. Mater., 2009, 161(2-3): 1122 -1130.

[14] Daghrir R, Drogui P, Robert D. Modified TiO2 for environmental photocatalytic applications: A review. Ind. Eng. Chem. Res., 2013, 52(10): 3581-3599

[15] Tayade R J, Surolia P K, Kulkarni R G, Jasra R V. Photocatalytic degradation of dyes and organic contaminants in water using nanocrystalline anatase and rutile $\mathrm{TiO}_{2}$. Sci. Technol. Adv. Mater., 2007, 8(6): 455- 462.

[16] Li F B, Gu G B, Li X J. The enhanced photocatalytic behavior of $\mathrm{Sb}_{2} \mathrm{O}_{3} / \mathrm{TiO}_{2}$ semiconductor nanopowder. Chinese Journal of Inorganic Chemistry, 2001, 17(1): 37- 42. 